\title{
Violência Interpessoal: E Agora, Doutor?
}

Renato Zamora Flores*

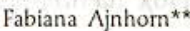

\section{RESUMO}

O presente artigo traça um perfil da importância do ensino de métodos que permitam aos médicos lidarem com a crescente violência à sua volta e a desenvolverem modelos teóricos que permitam ações sociais efetivas.

\section{INTRODUÇÃO}

$O$ conflito entre a importância da biologia $X$ a importância da cultura, na natureza humana, já pode ser percebido nas pinturas de cavernas do período paleolítico. No decorrer da história da civilizaçāo ocidental, este conflito, para compatibilizar a capacidade humana única de criar culturas complexas com a semelhança anatômica e funcional entre o Homo sapiens e os demais animais passou, ora, por períodos de maior influência de modelos culturais, ora, por períodos mais biologizantes.

Uma das fontes contemporâneas de atrito é a ansiedade apresentada pelos cientistas sociais em relação a autonomia de suas ciências, no que diz respeito à incorporação de aspectos biológicos da natureza humana no conjunto de seus paradigmas. Os fundadores das modernas disciplinas sociais e comportamentais, particularmente Émile Durkein na sociologia, Franz Boas na antropologia, Sigmund Freud na psicanálise e J. B. Watson na psicologia behaviorista, tiveram bastante cuidado em proteger seus filhotes do império biológico, resultado das grandes conquistas científicas da biologia e da medicina a partir do século XIX. ${ }^{27}$

Ao analisarmos o problema da crescente violência em nossa sociedade, a primeira pergunta que pode

PALAVRAS-CHAVE:

Violência;

Neurobiologia;

Ensino Médico;

Sociologia.
"Professor de Genética Médica e membro da Comissão de graduação do curso de Medicina da Universidade Federal do Rio Grande do Sul.

"Acadêmica do 10 " semestre e monitora da disciplina de Genética Médica do curso de Medicina da UFRGS. ser feita é: As ciências da vida, e dentre estas a medicina, têm alguma contribuição para o modelo teórico que utilizamos para entender a violência como fenômeno de nosso cotidiano? Minayo ${ }^{30,31}$ acha que não: 
"É, hoje, praticamente unânime, por exemplo, a idéia de que a violência não faz parte da natureza humana e que a mesma não tem raízes biológicas. Trata-se de um complexo e dinâmico fenômeno biopsicossocial, mas seu espaço de criação e desenvolvimento é a vida em sociedade. Portanto, para entendê-la, há que se apelar para a especificidade histórica". ${ }^{30}$

"O tema violência, porém, sempre foi considerado evento do mundo social e tradicionalmente tratado pela justiça e segurança pública... Hoje há no país uma respeitável produção científica, capaz de fundamentar sócio-historicamente análises epidemiológicas, dados gerais sobre "sub-causas" que compōem o que na área de saúde é classificado violência...". 31

Ou seja, as causas da violência são questões a serem abordadas, segundo Minayo ${ }^{31}$, como "eventos do mundo social", por isso qualificamos os cientistas sociais, filósofos e historiadores como os únicos habilitados para tal. Aos médicos cabe apenas atuar, "seja enquanto cidadãos preocupados com o rumo da sociedade brasileira, seja enquanto profissionais", "nas marcas que a violência deixa nos corpos e nas mentes da população que demanda sua atenção". Análises epidemiológicas necessitam pois, para sua correta interpretação, da supervisão de sociólogos ou historiadores.

O papel da medicina em todos os níveis de prevenção de comportamentos violentos e suas seqüelas não está em discussão. Ele é tão óbvio que é consensual.

É possível discutir a contribuição da medicina para o entendimento das causas de fenômenos como guerras ou outros grandes conflitos sociais que levam a situaçōes de violência, como o problema da divisão da terra, por exemplo. Esta argumentação, por motivos de espaço, orienta-se no sentido de interpretar a violência urbana. Mais do que prevenir ou curar feridas, as ciências da saúde são imprescindíveis na construção de um modelo teórico eficiente sobre essa forma de violência.

\section{DE QUE ESTAMOS TRATANDO?}

É dificil fazer uma classificação operacional de violência. Isto ocorre, provavelmente, por que fenômenos de causas e conseqüências diferentes são incluídos no amplo espectro desde conceito. Diferentes fatos com um mesmo nome. Um filósofo russo, Denisov, citado por Minayo $^{31}$, chega a perder as esperanças:
"Existem milhōes de fatores os mais diversos que incidem simultaneamente sobre a conduta humana, e todos os motivos do comportamento e da ação violenta passam pela mente."

Não é surpresa que, utilizando-se de definições como esta, as ciências sociais, em seu caminho solitário, tenham dificuldades de, no Brasil, promoverem ações concretas, baseadas em seus princípios teóricos, para atuar sobre o fenômeno da violência, especialmente a urbana.

A contribuição que as ciências da vida podem oferecer está no entendimento das causas últimas da violência. A distinção entre causas próximas e últimas, que com freqüência costuma escapar a compreensāo de cientistas dessa área, é fundamental para o entendimento desta proposta.

Quando, por exemplo, um indivíduo comete um assassinato, podemos analisar este fenômeno no seu contexto mais imediato: quais as relaçōes entre vítima e agressor, qual o contexto da interação social que levou a este desfecho, em que ambiente psicossocial estavam inseridos, etc. Estas são as causas próximas.

Podemos examinar, por outro lado, estes fenômenos em níveis mais genéricos. Quais as estruturas mentais que permitem ou não a um indivíduo matar outros da mesma espécie? Quais as vantagens ou desvantagens que levam os indivíduos a lançarem mão de condutas violentas? Por que algumas espécies de animais são mais agressivas do que outras, e, dentre estas, a nossa? Quais as semelhanças e as diferenças entre a violência nos seres humanos e em nossos parentes próximos, os grande primatas (chimpanzés, orangotangos e gorilas)? O que podemos aprender com eles?

Por isso, ainda que cada situação de violência tenha sua própria circunstância, o que a biologia nos ensina é que todas elas podem ser unificadas em algum ponto (ou, para sermos mais rigorosos, em alguns poucos pontos) da mente humana. Estas são as causas últimas.

\section{MAMÍFEROS VIOLENTOS E CÉREBROS DE MACACOS}

Quando olhamos para um chimpanzé percebemos a diferença profunda na aparência física entre ele e um Homo sapiens, apesar de uma homologia, entre a estrutura das proteínas que os compōem, de mais de $99 \%$. Entre nós e o resto dos animais há uma grande abismo que impede comparações: a cultura. 
O evolucionista Richard Dawkins ${ }^{12}$ sugere que fomos educados numa crença quase reverencial de que divisões no reino animal, como humanos $X$ animais, são causadas por eventos muitos singulares, o que não é obrigatoriamente verdade.

As guerras são uma forma de violência supostamente exclusiva da espécie humana: "Animais lutam, mas não fazem guerra". ${ }^{3}$ Talvez a verdade não seja bem assim.

Vários animais guerreiam. Formigas são as mais conhecidas, mas, como são muito diferentes de nós, não costumamos, com razão, levá-las em conta. Alguns mamíferos gregários, entretanto, como chimpanzés, mangustas e hienas, organizam-se em bandos e atacam grupos rivais com uma crueldade digna de seres humanos, incluindo morte de indivíduos indefesos, já fora de combate ou de filhotes. As razōes da luta são igualmente semelhantes àquelas vistas no Homo sapiens: território e recursos do meio ambiente. ${ }^{29}$

Outro exemplo: a violência nos grandes centros urbanos. Sou$\mathrm{za}^{38}$ mostra que homens são 11 vezes mais vítimas de homicídios do que mulheres no Brasil. Os índices de mortalidade crescem abruptamente a partir dos quinze anos. Na cidade de Nova York, homicídios são a principal causa de morte entre 14 e 19 anos. ${ }^{42}$ Em uma análise de uma epidemia de homicídios por guerra de gangs na cidade de Los Angeles, Hutson e cols. ${ }^{24}$ encontraram que, entre 5.541 mortos, $85 \%$ estavam entre 15 e 34 anos; $93 \%$ eram homens; $64 \%$ eram membros de gangs e $93 \%$ eram hispânicos ou afro-americanos.

Seria apenas a pobreza? Esta é sem dúvida um fator de risco não só para a violência como também para a morte puerperal, injúrias acidentais, queimaduras, infeções respiratórias, abandono escolar, gestação na adolescência e, como conseqüência, a perpétua permanência em situação de pobreza. ${ }^{26}$

A resposta é não. Já em 1985, quando os Centers for Disease Control, em Atlanta (USA) iniciavam as atividades do Violence Epidemiology Branch, um comentário no JAMA dizia:

Liberais pensam que a causa [da violência] é a pobreza, conservadores acusam a liberdade. Ambas explicaçōes são inadequadas... Se há uma única chave para o alto e crescente aumento da violência interpessoal nos Estados Unidos, é a violência contra a criança. $^{8}$
Dodge e cols., ${ }^{16}$ em um estudo clássico sobre a neuropsicologia da violência que avaliou 309 crianças de quatro anos de idade, 15\% vítimas de abusos físicos, concluíram que crianças maltratadas desenvolvem com maior probabilidade processos deficientes de informação social, percebem atitudes agressivas com maior freqüência no comportamento alheio e não possuem estratégias competentes de solução de conflitos interpessoais. Este padrão de comportamento, por outro lado, estimula o desenvolvimento de comportamentos agressivos. A experiência de violência física leva a criança a perceber e conceitualizar o mundo de uma maneira anormal que, posteriormente, perpetua o ciclo da violência.

O sofrimento psicológico aparentemente fixa patologicamente determinadas memórias, impedindo que o indivíduo integre uma experiência traumática no contexto de suas demais experiências:

"O cérebro isola experiências dolorosas e as remove do processo dinâmico do entendimento... O trauma de um acidente que cause cegueira [de origem psicogênica], por exemplo, pode fixar imagem visual, já que o cérebro fica impossibilitado de reconhecerse frente a tal experiência visual." 37

Estas alterações neurobiológicas da memória, causadas por experiências traumáticas, progressivamente aumentam a vulnerabilidade aos mesmos agentes estressores. ${ }^{33}$ Existe, portanto, uma base neurológica para o fenômeno de aumento progressivo da violência interpessoal.

A história está repleta de exemplos da utilização inadequada de modelos biológicos sobre comportamento agressivo (veja-se, por exemplo, Flores e Loreto, $\left.{ }^{19}\right)$. Algumas pesquisas bastante atuais parecem muito promissoras. Os resultados apresentados por Albert e cols. ${ }^{1}$ sugerem que a agressão no Homo sapiens guarda muitos correlatos anatômicos, fisiológicos e comportamentais com a agressão defensiva em outros mamíferos. No cérebro, esta forma de agressão aumenta com estímulos da amígdala e é inibida por algumas áreas do hipotálamo e região septal.

Este achado permite uma importante inferência neuropsicológica: grande parte da agressão cometida pelos seres humanos parte de uma percepção prévia de ter sido agredido. 
É uma boa hipótese, mas outras informações podem ser ainda agregadas. Talvez uma comparação com nossos primos antropóides possa ajudar-nos a entender ainda melhor porque isso acontece. Quiçá o cérebro de primata gregário que possuímos esteja colaborando no fato de que os maiores índices de criminalidade e de vitimização são encontrados em jovens do sexo masculino e de classes sociais mais baixas.

A psicologia evolucionista nos ensina que os homens (como vários outros macacos machos) competem por status por todos os meios disponíveis. A razão última da violência, cometida por jovens excluídos, seria um display, ${ }^{*}$ para demonstrar aos membros do grupo sua capacidade de manter o status. A maioria dos homicídios citados acima foi cometida contra pessoas conhecidas e com testemunhas: nestes casos a violência foi basicamente uma perfomance, uma demonstração social de força.

Em comunidades, como as grandes cidades, onde os relacionamentos interpessoais e sociais se desagregam, o lucro pessoal para estes indivíduos é quase imediato, como um maior acesso a recursos ambientais, entre eles, o sexo. ${ }^{41}$ Nestes grupos, indivíduos violentos são mais bem-sucedidos, mesmo que por pouco tempo.

Para muitos mamíferos sociais, primatas humanos e não-humanos inclusive, ser alijado de seu grupo ou estar em descanso na hierarquia apresenta modificações psiconeurológicas que o predispõem a correr riscos, a agredir e a perder o autocontrole com maior facilidade. Estas modificações, mediadas pela diminuição da quantidade de serotonina em alguns neurônios do tronco cerebral, são reversíveis e funcionam em uma via de duas mãos. A ascensão social e a vivência em posição superior podem ser percebidas não só no cérebro, mas também na sua supra-renal e no fígado. ${ }^{3}$

A administração de substâncias capazes de elevar os níveis de serotonina, como Prozac, tendem a orientar a conduta no sentido de uma autoconfiança assertiva, porém calma e raramente violenta. ${ }^{41}$ Prado Lima e $\operatorname{cols}^{34}$ conseguiram redução no nível de agressividade de mães que espancaram seus filhos, com o uso de carbonato de lítio, que aumenta a quantidade de serotonina.

Entretanto outros mecanismos podem estar envolvidos. Mann ${ }^{28}$ sugere que dois outros neurotransmissores estão relacionados com comportamentos violentos. O uso de drogas antipsicóticas para controle destes comportamentos sugere que há uma relação entre atividade dopaminérgica e violência. A dopamina, possivelmente, está relacionada com mecanismos de dominância e submissão. Supōe-se também que sistemas adrenérgicos possam estar envolvidos, já que drogas como álcool, cocaína e anfetaminas aumentam a liberação de neurotransmissores deste grupo e o seu uso está relacionado com o aumento potencial de comportamentos agressivos.

Por que nosso cérebro funciona assim? Por razōes evolutivas. Para os indivíduos excluídos do grupo social, sobram duas opções: aceitar a situação ou lutar contra ela. Neste caso, haverá uma óbvia pressão da seleção natural para promover genes que favoreçam respostas radicais que aumentem as chances de sobrevivência e reprodução do indivíduo. Como vivemos em um ambiente que difere bastante daquele onde fomos desenvolvidos há milhões de anos atrás, certos centros cerebrais ficam expostos a estímulos que não existiam, ou eram de intensidade diferente, em nosso passado de caçadores-coletores.

A violência não tem um componente genético imediato como a fenilcetonúria ou a Doença de Huntington. A participação dos genes neste fenômeno social é de dotar o cérebro do ser humano de mecanismos defensivos segundo a ótica das populações primitivas para situações extremas.

\section{MEDICALIZANDO A VIOLÊNCIA INTERPESSOAL}

Segundo Flores e Loreto, ${ }^{19}$ a violência urbana refere-se, em sua maior quantidade, a crimes envolvendo atos violentos interpessoais, um conjunto que inclui desde agressões pessoais - usualmente contra pessoas muito conhecidas - e a patrimônios, até homicídios e crimes violentos de trânsito. Ao estudarmos esta categoria de eventos sociais, o que mais atrai a atenção é sua distribuição estatística. Ao contrário de outras variáveis que apresentam uma média em torno da qual os pontos se distribuem, a maioria dos atos violentos são cometidos por uns poucos indivíduos.

Elliott, ${ }^{17}$ comparando oito estudos sobre indivíduos violentos, conclui que, em sete, a prevalência de anormalidades neurológicas

-Termo da etologia que significa um conjunto de comportamento cuja função é informar con-

especificos de um determinado estado mental. 
e neuropsicológicas era muito maior do que em controles ou na população em geral. Em um destes estudos, 10 mil homens nascidos em 1945 foram analisados aos 45 anos de idade, em 1990, para detectar a presença de comportamentos violentos no decorrer de suas vidas. Pesquisadores identificaram 627 que foram classificados como agressores crônicos envolvidos recorrentemente com situações de violência. Destes, apenas $6 \%$ eram responsáveis por $71 \%$ dos homicídios, $73 \%$ dos estupros e $69 \%$ das agressões graves.

A taxa de criminalidade dos doentes mentais tem aumentado bastante desde a década de 60 . Na Inglaterra, por exemplo, na primeira metade do século a freqüência de criminalidade de pacientes psiquiátricos era a mesma da população em geral. Atualmente está em torno de $40 \%$, cerca de 2,5 vezes mais que na população em geral. A causa mais provável é o processo de desinstitucionalização dos doentes mentais e uma progressiva criminalização de comportamentos psicopatológicos. ${ }^{32}$ A maior parte dos indivíduos psicóticos ou esquizofrênicos que cometem abusos sexuais não tinha diagnóstico até serem presos. ${ }^{11}$

Além disso, entre deficientes mentais, a freqüência de indivíduos que cometeram abusos sexuais chegou a ser seis vezes maior do que na população em geral, ainda que no padrão de agressão fosse semelhante. ${ }^{13}$

Algumas formas de violência interpessoal são, aparentemente, de origem cultural. Por exemplo, Heise ${ }^{22}$ sugere que atitudes e crenças sociais fundamentam a violência doméstica contra a mulher. Giffin, ${ }^{21}$ citando a própria Heise, afirma em relação à violência de gênero: "Em sua maioria, os homens violentos não são doentes mentais."

Entretanto, em uma revisão da literatura, Holtzworth-Munroe \& Stuart $^{23}$ sugerem a existência de três subtipos de agressores conjugais. Destes, dois apresentam altas freqüências de psicopatologias e, o terceiro, freqüência entre baixas e moderadas. Ainda que não seja possível produzir uma estatística de precisão, é razoável estimarse em, pelo menos, $50 \%$ a porção de agressores domésticos portadores de patologias mentais.

Agressores conjugais também experimentam mais estresse do que os homens não agressivos: hipertensão arterial e doenças cardíacas, úlceras e dores crônicas, ainda que sejam menos lesionados nos confrontos: apenas $2 \%$ tinham sofrido lesões físicas versus $15 \%$ das esposas. ${ }^{6}$

A psicopatologia dos pais é um importante determinante da negligência e violência contra os filhos em $57 \%$ dos casos de uma amostra de 378 famílias. ${ }^{25}$ Estes dados, combinados com a estimativa de que pelo menos $2,4 \%$ das crianças sofrem abusos sexuais e $5,2 \%$ das crianças são fortemente agredidas, cada ano, nos Estados Unidos, ${ }^{18}$ dão uma dimensão do sofrimento psicológico de uma cultura inadequada em termos de saúde.

Estas informações parecem desconhecidas para alguns cientistas sociais:

"A rigor, a violência não é um tema da competência da saúde. Ela, na verdade, é um termômetro das condições e das relações sociais de uma determinada sociedade. ${ }^{\prime 31}$

\section{QUESTÕES MÉDICAS}

Ainda que uma série de mitos sociais criem barreiras para uma intervenção, a ética obriga o profissional a não se omitir em um caso de violência doméstica. Quando um abuso não é diagnosticado, o tratamento pode ser inadequado e potencialmente perigoso. Entretanto é possível identificar uma série de razões para que um médico não trate deste assunto com seu paciente: medo de criar constrangimento ao paciente por invadir uma área socialmente privada, sensação de impotência frente ao fenômeno, medo da perda de controle da situação e sua conseqüente piora e até o rígido esquema de tempo das consultas a que estão submetidos. ${ }^{39}$

As conseqüências são bastante ruins. A falta de experiência em lidar com violência leva, com freqüência, o médico a subestimar a possibilidade de que algum de seus pacientes, mulheres ou crianças, especialmente, seja vítima de abusos.

Mesmo que, desde 1992, haja um alerta do American College of Obstetricians and Gynecologist em relação à violência doméstica, ${ }^{35}$ em uma amostra destes profissionais, $50 \%$ achavam que o assunto seria melhor tratado por outras especialidades. De um total de dez cenários de violência doméstica, $75 \%$ destes médicos deixaram de identificar pelo menos uma das situaçōes. ${ }^{7}$

Especialmente durante a gestação, mulheres estão em maior risco de abuso: entre $4 \%$ a $17 \%$. Destas, $1 / 3$ necessita de atendimento 
médico pela agressão. O risco é aumentado se a gestação não foi desejada, se a gestante é jovem, de baixo nível sócio-econômico e reside em más condições de habitação. ${ }^{20,40}$

O papel de pediatra é especialmente relevante. Proporcionalmente, há um excesso de jovens tanto entre as vítimas como entre os agressores. Além disso, história de vitimização física ou sexual, presença de agressividade aumentada ou distúrbios na infância ou juventude são importantes fatores de rico para criminalidade e comportamento violento na vida adulta. ${ }^{36}$

As recomendações da American Academy of Pediatrics ${ }^{42}$ são no sentido de orientar-se os esforços na prevenção da violência por meio de intervenções educacionais que ofereçam opções de ação nãoviolenta, incluindo técnicas de solução de conflito e mediação, que melhorem a competência social e o desenvolvimento da auto-estima.

Também, devido ao aumento do número de pacientes violentos, alguns hospitais gerais foram obrigados a desenvolver estratégias para seu manejo, através de equipes multidisciplinares. Um atendimento especializado para situações de violência no contexto hospitalar evita danos aos próprios pacientes, a outros pacientes e a funcionários. ${ }^{4}$

\section{CONCLUSÕES}

As orientações do Council of Affairs da American Medical Association sugerem que devemos desenvolver nos profissionais a atenção para problemas de violência, incluindo fatores de risco, prevalências dos principais fenômenos, seqüelas e métodos de manejo. ${ }^{10}$ Para tal é necessária uma readaptação de currículos para sua inclusão nos cursos de Medicina. ${ }^{35}$

No Brasil o assunto toma ainda pouca atenção da classe médica: uma pesquisa no banco de dados LILACS (Literatura Latino Americana e do Caribe em Ciências da Saúde), desde 1982 até hoje, revelou apenas três publicações relacionando ensino médico e violência. ${ }^{2,5}$ e 15 No curso de Medicina da Universidade Federal do Rio Grande do Sul, por exemplo, foi possível detectar apenas aulas eventuais e dispersas em algumas disciplinas (Programação e Proteção da Saúde da Criança, Genética Médica, Medicina Legal, Pediatria e Psiquiatria).

Por isso, é necessário chamar a atenção de médicos, e em especial dos professores, nos cursos de Medicina, e de preceptores, nas residências médicas, sobre a necessidade da inclusāo do tema "Violên- cia" como um conteúdo específico dos currículos de diversas disciplinas de graduação e mesmo como uma disciplina específica em cursos de pós-graduação. Se uma das funções dos médicos é salvar vidas, a prevenção e atendimento de vítimas da violência será uma área de trabalho muito ampla nas próximas décadas e com tendências nítidas de ampliação do seu mercado de trabalho.

\section{SUMMARY}

This article outline the importance of teaching methods that allow phisicians to struggle with the crescent violence and develop theoretical models to permit effective social actions.

\section{KEY WORDS}

Violence; Neurobiology; Medical education; Sociology.

\section{AGRADECIMENTOS}

À jornalista Lúcia E. N. Santos e ao Prof. Kristensen (Depto. de Psicologia, UFRS) pela análise crítica do manuscrito e sugestões. A FINEP, CNPq, PROPESP (UFRS) pelo financiamento parcial de pesquisas e atividades de extensão que propiciaram este artigo.

\section{REFERÊNCIAS BIBLIOGRÁFICAS}

1. Albert, D.J., Walsh, M.L. \& Jonik, R.H. Aggression in humans: What is its biological foundation? Neurosciences and Biobehavioral Reviews, 17: 405-425, 1993.

2. Albuquerque, I.C., Correa, H.C., Strassburger, M., \& Artnak, M. Urgências psiquiátricas na prática médica. Acta med. (PortoAlegre): 119-32, jun. 1984- jul. 1985

3. Blanchard, D.C., Sakai, R.R., McEwen, B., Weiss, S.M. \& Blanchard, R.J. Subordination stress: behavioral, brain and neuroendocrine correlates. Behavioral Brain Research, 58: 113-21, 1993.

4. Brailey, J., Lange, R., Baggoley, C., Bond \& Harvey, P. He violente management team-an approach to agressive behavior in a general hospital. The Medical J. of Australia, 161:254-8, 1994.

5. Cardoso Filho, Mário da Costa. O médico e a violência: limites da dignidade In: Academia Nacional de Medicina. Conferência do Rio de Saúde, Meio-Ambiente e Desenvolvimento, ONGS - Rio/92. Anais. Rio de Janeiro, Academia Nacional de Medicina, 1992.p.67-70 
6. Cascardi, M., Langhinrichsen, J \& Vivian, D. Marital agression: impact, injury and health correlates for husband and wives. Archives of internal Medicine, 156:1178-84, 1992.

7. Chambliss, L.R., Bay, R.C. \& Jones III, R.F. Domestic violence: an educational imperative? Am. J. Obstet. Gynecol, 172:1035-8, 1995.

8. Check, W.A. Homicide, suicide, other violence gain increasing medical atention. JAMA,254(6): 721-30,1985.

9. Council of Ethical and Juridical Affairs (AMA). Physician and domestic violence ethical considerations. JAMA, 267(23): 3190-3,1992.

10. Council of Scientific Affairs (AMA). Violence against women relevance for medical practitioners. JAMA, 267(23):3184-88, 1992.

11. Craissati, J. \& Hodes, P. Mentaly ill sex affenders. British J. of Psychiatry, 161: 846-9, 1992.

12. Dawkins, R. O rio que saía do Éden, Rio de Janeiro, Rocco,1996.

13. Day, K. Male mentally handicapped sex offenders. British J. of Psychiatry, 165: 630-9, 1994.

14. Dennett, D. Consciousness explained. Boston, Little Brown, 1991.

15. Deslandes, S. F. Prevenir a violência: um desafio para profissionais de saúde. Rio de Janeiro, CLAVES, 1994. 39 p.

16. Dodge, K.A., Bates, J.E. \& Pettit, G.S. Mechanism in the cycle of violence.Science, 250:1678, 1990.

17. Elliott, F.A. Violence, the neurologic contribution: an overview. Arch. Neurology, 49:595-603, 1992.

18. Finkelhorn, D. \& Dziuba-Leatherman, J. Children as victims of violence: a national survey. Pediatrics, 94(4): 413-20, 1994.

19. Flores, R.Z. \& Loreto, E.L. Contribuição da biologia para um modelo social. Ciências e Ambiente (Universidade Federal de Santa Maria), 12:65-76, 1996.

20. Gazmararian, J. A., Adams, M.M., Saltazman, L.E. and cols. The relationship between pregnancy intendedness and physical violence in mother of newborns. Obstent. Gynecol, 85:1031-8, 1995.

21. Giffin, K. Violência de gênero, sexualidade e saúde. Cadernos de Saúde Pública, RJ, 10 (supl.1): 146-55, 1994.

22. Heise, L. Gender-based abuse: the global epidemic. Cadernos de Saúde Pública, RJ, 10(supl.1): 135-45,1994.
23. Holtzworth-Munroe, A. \& Staurt, G. Typologies of males batteres: three subtypes and the diference among them. Psychological Bulletin, 116(3): 476-97, 1994.

24. Hutson, H.R., Anglin, D., Kyriacou, D.N., Hart, J. \& Sperars, K. The epidemic of gang-related homicides in Los Angeles Country from 1979 and 1984. JAMA. 274(13): 1031-6, 1995.

25. Kelleher, K., M., Hollenberg, J \& Fischer, E. Alcohol and drug disordes among physically abusive and negletful parents in a communitybased sample. Am. J. Public Health, 84(10):1586-90, 1984.

26. Kliegman, R.P. Perpetual poverty: child health and the underclass. Pediatrics, 89(4): 710-2, 1992.

27. Lumsden, C.J. \& Wilson, E.O. The promethean fire - reflections on the origin of mind. Cambridge, Harvard Univ. Press, 1983.

28. Mann. J.J. Violence and agression IN: Kupfer, D.J. \& Floyd, E.B. (eds) Psychofarmacology: the fourth generation of progress. New york, raven press, 1995.

29. Masson, J.M. \& McCarthy, S. When elephant weep - the emocional lives of animals. New York, Dellacorte Press, 1995.

30. Minayo, M.C.S. A violência social sob a perpesctiva da saúde pública. Cadernos de Saúde Pública, RJ, 10(supl.1): 07-18, 1994.

31. Minayo, M.C.S. A abordagem da violência na formação médica. R. Bras. Educ. Méd. RJ, 19(1/3): 20-24, 1995.

32. Modéstia, J \& Ammann, R. Mental disordes and criminal behaviour. British J. of Psychiatry, 166: 667-75, 1995.

33. Post, R. M. Transduction of psychosocial stress into the neurobiology of recurrent affective disorder. Am. J. Psychiatry, 149: 999-1010, 1992.

34. Prado-Lima, P.A.S., Knijnik, L.B., Juruena, M.F.P. \& Padilha, A.V. Effects of lithium on child abusing mothers: a preliminary reporty. 1996. Em preparação.

35. Randall, T. do American College of Obstetricians and Gynecologist renews domestic violence campaing, calls for changes in medical school curricula.JAMA, 267(23):3131, 1992.

36. Rivara, F.P. \& Farrington, D.P. Prevention of violence - role of pediatrician, Arch. Pediatr. Adolesc. Medicine, 149:421-9, 1995.

37. Rosenfield, I. The strange, familiar, and forgotten - an anatomy of consciousness. Ney York, First Vintage Books, 1993. 
38. Souza, E.R. Homicídios no Brasil: o grande vilão da saúde pública na década de 80. Cadernos de Saúde Pública, RJ, (supl.1): 45-60, 1994.

39. Sugg, N.K. \& Inui, T. Primary care physicians'response to domestic violence - opening the pandora's box. JAMA, 267(23): 3157-60,1992.

40. Wesbster, J., Sweett, S. \& Stolz, T.A. Domestic violence in pregnancy. The Medical J. of Australia, 161:466-70, 1994.

41. Whrigt, R. The biology of violence. The Ney Yorker, 71(3): 6877,1995 .

42. Wilson-Brewer, R. \& Spivak, H. Violence prevention in schools and other advocate. Pediatrics, 94(4): 623-30, 1994.

\section{Endereço dos Autores}

Dept $^{\circ}$ de Genética, Universidade Federal do Rio Grande do Sul

Caixa Postal 15031

91501-970 - Porto Alegre - RS 